\title{
Cork-oak woodlands as key-habitats for biodiversity conservation in Mediterranean landscapes: a case study using rove and ground beetles (Coleoptera: Staphylinidae, Carabidae)
}

\author{
Pedro Martins da Silva $\cdot$ Carlos A. S. Aguiar · Jari Niemelä • \\ José Paulo Sousa $\cdot$ Artur R. M. Serrano
}

Received: 7 June 2008/ Accepted: 14 November 2008/Published online: 30 November 2008

(C) Springer Science+Business Media B.V. 2008

\begin{abstract}
Land-use intensification in Mediterranean agro-forest systems became a pressure on biodiversity, concerning particularly the woodland sensitive species. In 2001, the effects of a land-use gradient from old-growth cork-oak forest to a homogeneous agricultural area were assessed using rove beetles as indicators in a Mediterranean landscape. The aim was to find which species were negatively affected by land-use intensification at the landscape level and whether they benefited from cork-oak patches occurring along the land-use gradient. A total of 3,196 rove beetles from 88 taxa were sampled from all landscape types. Agricultural area recorded significantly higher numbers of abundance and species richness in relation to the cork-oak mosaics, i.e. the old-growth forest and the managed agro-forest landscapes (montados). Moreover, $70 \%$ of rove beetle indicator species common enough to be tested by IndVal displayed their highest indicator value for agriculture, showing a lower number of woodland indicators in comparison to ground beetles. Nevertheless, one rove beetle taxon was considered a specialist of closed woodland mosaics while no specialist ground beetle was found for that landscape typology. Some rare rove beetle species were also important in typifying diversity patterns of oldgrowth cork-oak forests. Hence, future management in Mediterranean landscapes should take into account not only indicator species common enough to be tested by IndVal, but also rare and endemic species. Considering the added value of cork-oak woodland cover for sensitive rove and ground beetle diversity, the strengthening of cork-oak woodland connectivity seems to be a crucial management that is required in agricultural Mediterranean landscapes.
\end{abstract}

P. M. da Silva $(\varangle)$. C. A. S. Aguiar · A. R. M. Serrano

Centre for Environmental Biology, Faculty of Sciences, University of Lisbon, R. Ernesto de Vasconcelos Ed. C2-2 ${ }^{\circ}$ Piso, Campo Grande, 1749-016 Lisbon, Portugal

e-mail: pgpmartins@yahoo.co.uk

J. Niemelä

Department of Biological and Environmental Sciences, University of Helsinki, P.O. Box 65, 00014 Helsinki, Finland

P. M. da Silva · J. P. Sousa

IMAR-Coimbra Interdisciplinary Centre, Department of Zoology, University of Coimbra, Largo Marquês de Pombal, 3004-517 Coimbra, Portugal 
Keywords Agro-forest mosaic - Biodiversity conservation - Epigaeic Coleoptera · Indicator value $\cdot$ Land-use intensification $\cdot$ Quercus suber

\section{Introduction}

Traditional management practices in Mediterranean landscapes dominated by cork-oak woodland areas are known to provide complex and dynamic agro-forest mosaics (Verdú et al. 2000; Taboada et al. 2006). This low intensity of land-use disturbance is able to sustain high levels of biodiversity due to species turnover between agriculture and woodland habitats (e.g. Romero-Alcaraz and Ávila 2000; Woodcock et al. 2005). However, land-use intensification occurring in the last decades led to the loss of natural and semi-natural habitats (Rainio and Niemelä 2003), resulting in a pressure on woodland specialist species (Niemelä et al. 1993; Magura et al. 2000). These usually occupy narrow niches in old and unfragmented habitats, having few suitable habitats for dispersion and so being more sensitive to the effects of habitat disturbance than generalists (Halme and Niemelä 1993; Niemelä and Baur 1998; Petit and Usher 1998; Kotze and O’Hara 2003; Buddle et al. 2006). Hence the implementation of such accurate ecological indicators is required for conservation and management of dynamic agro-forest ecosystems. In this context, the project "Biodiversity Assessment Tools" (BIOASSESS: http://www.nbu.ac. uk/bioassess/) targeted the development of a set of ecological indicators able to monitor biodiversity changes in human-disturbed landscapes according to a land-use gradient (Sousa et al. 2006). One of the taxa studied in the BIOASSESS was ground beetles (e.g. Martins da Silva et al. 2008). In theory, rove beetles are as well suitable bio-indicators in agro-ecosystems since they are also dominant (in some cases more than ground beetles) in terms of abundance, diversity and predatory activity in those landscapes (Shah et al. 2003; Hofmann and Mason 2006). Rove beetles also occur in a wide range of habitats and are strongly influenced by the structure of cultural landscapes and different intensities of landuse management (Bohac 1999; Markgraf and Basedow 2002). However, rove beetles have not been so frequently used as bio-indicators in comparison to ground beetles, largely due to taxonomic constrain and lack of species ecology information (Bohac 1999; Andersen and Eltun 2000). These drawbacks are more prominent in the Mediterranean region where rove beetles are particularly species-rich and poorly known, with a substantial number of endemics, namely from the Iberian Peninsula and specifically from Portugal (e.g. Drugmand and Outerelo 1997; Martins da Silva et al. 2006). In this study, we used rove beetles as indicators of land-use intensification, comparing its results with those previously obtained for ground beetles (Martins da Silva et al. 2008). The aim was to assess the effects of land-use intensification on beetle diversity patterns at the landscape scale, identifying which species benefited from woodland habitats along the land-use gradient. Such species should be a key monitoring tool in future conservation and management strategies.

\section{Materials and methods}

Site description and beetle sampling

The field work was conducted in 2001 in typical Mediterranean cork-oak areas (Quercus suber) under different types of management. The sampling sites were located in the consolidated alluvial plain of the river Tagus, $20 \mathrm{~km}$ east of Lisbon, Portugal (ca $42^{\circ} 50^{\prime} \mathrm{N}$ 
$\left.51^{\circ} 50^{\prime} \mathrm{E}\right)$. Land-use gradient ranged from unmanaged old-growth cork-oak woodland to an intensively managed agricultural field.

The old-growth cork-oak woodland was located in a buffer zone for military purposes. This situation caused a low level of management in this site over the last 50 years, resulting in a closed woodland dominated by cork-oak trees, despite the presence of maritime pine (Pinus pinaster) and umbrella pine (Pinus pinea).

The agricultural system was, since 1988, a homogeneous and permanently irrigated alfalfa field (Medicago sativa). Alfalfa, used as fodder, was sown for the first time in April 2001, mowing occurred four to five times each year (April-August), in the expected 7 years of hay exploitation. Three mineral fertilisations ( $\mathrm{N}, \mathrm{P}, \mathrm{K}-8,24,24$, respectively) of $300 \mathrm{Kg} / \mathrm{ha}$ were made each year.

The intermediate land-use intensification levels comprised three managed agro-forest mosaics (montados). They were privately owned by an agro-forestry company ("Companhia das Lezírias") for multiple uses, resulting in different landscape typologies (Sousa et al. 2004): a closed montado, where pruning has been done over 2 years before sampling; an open montado, with patches of natural grassland subjected to occasional grazing; and a montado, dominated by pastures with higher management level of extensive grazing. In each landscape type, a grid of 16 sampling points was established with four pitfall traps per point; the sampling protocol was the same used for ground beetles (see details in Martins da Silva et al. 2008). Table 1 summarises the habitat heterogeneity occurring within each studied landscape type (details in Sousa et al. 2004). Identification of rove beetle species was based on an extensive literature, but mainly on the works of Freude et al. (1964), Coiffait $(1972,1974,1978,1982,1984)$ and Outerelo and Gamarra (1985). Due to the lack of proper identification keys, the identification of several Aleocharinae species was not achievable.

Table 1 Habitat heterogeneity and major interventions on each landscape (numbers indicate number of sampling points at each habitat/land-use type)

\begin{tabular}{|c|c|c|c|c|c|}
\hline \multirow{3}{*}{$\begin{array}{l}\text { Habitat types } \\
\text { and interventions }\end{array}$} & \multicolumn{4}{|c|}{ Cork-oak mosaics } & \multirow[t]{3}{*}{ Agriculture } \\
\hline & \multirow[t]{2}{*}{ Old-growth } & \multicolumn{3}{|c|}{ Managed montados } & \\
\hline & & Closed & Open & Pastures & \\
\hline Closed woodland & 8 & 11 & 4 & 4 & \\
\hline Open woods & 3 & 5 & 9 & 6 & \\
\hline Shrub area & 3 & & & 1 & \\
\hline Grassland & 2 & & & & \\
\hline Pasture & & & 3 & 5 & \\
\hline Agriculture & & & & & 16 \\
\hline Understorey & $\begin{array}{r}\text { With } 10-15 \\
\text { years old }\end{array}$ & $\begin{array}{l}\text { Removal every } \\
6-8 \text { years }\end{array}$ & $\begin{array}{l}\text { With } 8 \text { years } \\
\text { old }\end{array}$ & $\begin{array}{l}\text { Strongly } \\
\quad \text { reduced }\end{array}$ & \\
\hline Interventions & None & Pruning & $\begin{array}{l}\text { Occasional } \\
\text { grazing }\end{array}$ & $\begin{array}{l}\text { Extensive } \\
\text { grazing }\end{array}$ & $\begin{array}{l}\text { Intensively } \\
\text { irrigated field }\end{array}$ \\
\hline Management level & None & Low & Medium & Medium & High \\
\hline
\end{tabular}

Old-growth: unmanaged cork-oak woodland; closed: montado dominated by closed woodlands; open: dominated by open woodlands; pastures: montado with more proportion of pasture areas in relation to the other mosaics; agriculture: managed monoculture of alfalfa 
Data analysis

Rove beetles activity densities and number of species found at each landscape type were compared by an ANOVA, followed by a Tukey test. If assumptions of homogeneity of variances and normality (verified previously using Bartlett and Kolmogorov-Smirnov tests, respectively) were not met, data were log transformed. All the above statistical calculations were made using the SigmaStat software (SPSS 13.0).

Regarding rove beetle richness, species accumulation curves were calculated in "Species Diversity and Richness" 3.0 software as the mean score after 100 randomisations, in order to check the species inventory efficiency and completeness in the studied sampling sites (e.g. Moreno and Halffter 2000; Hortal et al. 2006). Both rove and ground beetles' diversity patterns, along the land-use gradient, were analysed by multivariate techniques. Firstly, a detrended correspondence analysis (DCA) based on beetle species composition was performed to identify the gradient length. Subsequently, a canonical correspondence analysis (CCA) was done using log transformed data and based on the "sampling points versus taxa" data matrices. Statistical significance of the canonical axes was evaluated by a Monte Carlo permutation test. CCAs were performed in CANOCO 4.0 software.

Indicator species of each landscape type were identified for both beetle families using the Indicator Value (IndVal) method (Dufrêne and Legendre 1997). A previous step of this analysis was to obtain an a priori site typology using a hierarchical clustering method (Ward method) based on the Bray-Curtis similarity distances. Hence, the five studied landscape types were grouped according to the structure of the vegetation cover which was formed due to different land-use intensifications (Fig. 1, but see also Table 1). The first level of the classification grouped all sites. The second level separated "agriculture" from all landscapes dominated by cork-oak patches ("cork-oak mosaics"). The third level distinguished landscapes dominated by closed woodlands ("old-growth" and "closed montado") from landscapes dominated by open areas ("open montado" and "pastures") and the fourth separated all these landscape typologies (Fig. 1). The second step of this analysis was to identify the indicator species of each group of the site typology. According to Dufrêne and Legendre (1997), where species had the highest IndVal value they were used to indicate that group. Indicator values of 25 were considered the minimum level for the index (Dufrêne and Legendre 1997) as well as species with indicator values of at least 80 were regarded as specialists in particular landscape types (Pohl et al. 2007).

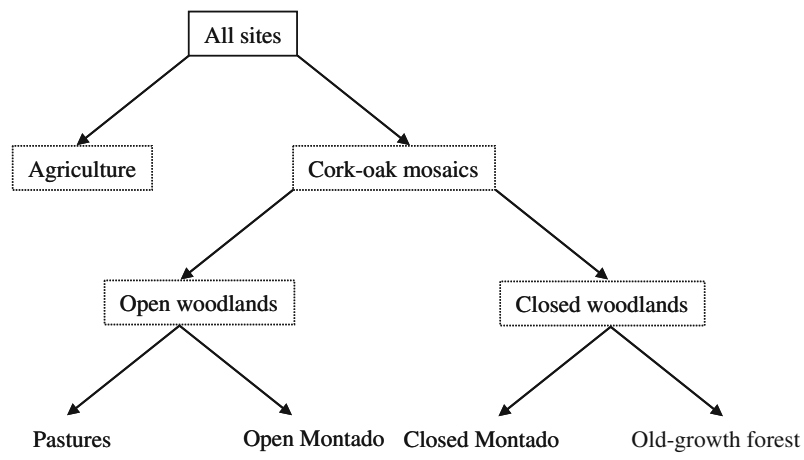

Fig. 1 Site a priori classification using an hierarchical clustering method based on the Bray-Curtis similarity distances. The landscape typology was based on the proportion of the five main habitat/land-use types 
A randomisation procedure among site groups was performed, using 250 permutations, to test the significance of IndVal (Dufrêne and Legendre 1997).

\section{Results}

Abundance and species richness

Rove beetles comprised about $21.7 \%$ of all sampled beetles (32.8\% were ground beetles). A total of 3,196 rove beetle specimens belonging to 88 taxa were recorded in all landscape types. Mean abundance and species richness were significantly higher in the agricultural field (total $S=61$ ) than in landscapes of cork-oak mosaics (total richness was lower in the closed montado: $S=24$ ) (Fig. 2a, b). Regarding these abundance and richness, differences between the forested and open areas within each landscape type were not significant (Fig. 2a, b). Species accumulation curves performed for all study sites revealed that sampling effort did not achieve the rove beetle species inventory completeness, as the asymptote (the curve "plateauing") was not obvious even for the richest agricultural landscape (Fig. 3).

The dominant taxa were Atheta sp. (19.2\%), Xantholinus longiventris Heer (11.9\%), Aleochara bipustulata (Linnaeus; 8.95\%), Ocypus aethiops (Waltl; 8.51\%), Sepedophilus

Fig. 2 Rove beetle abundance (a) and richness (b) along the land-use intensification gradient (mean values and SE). Old, oldgrowth; Clo, closed montado; Ope, open montado; Pas, pastures; Agr, agriculture (shaded bars forested areas and white bars open areas). The asterisk indicates different groups after Tukey test $(P<0.05)$
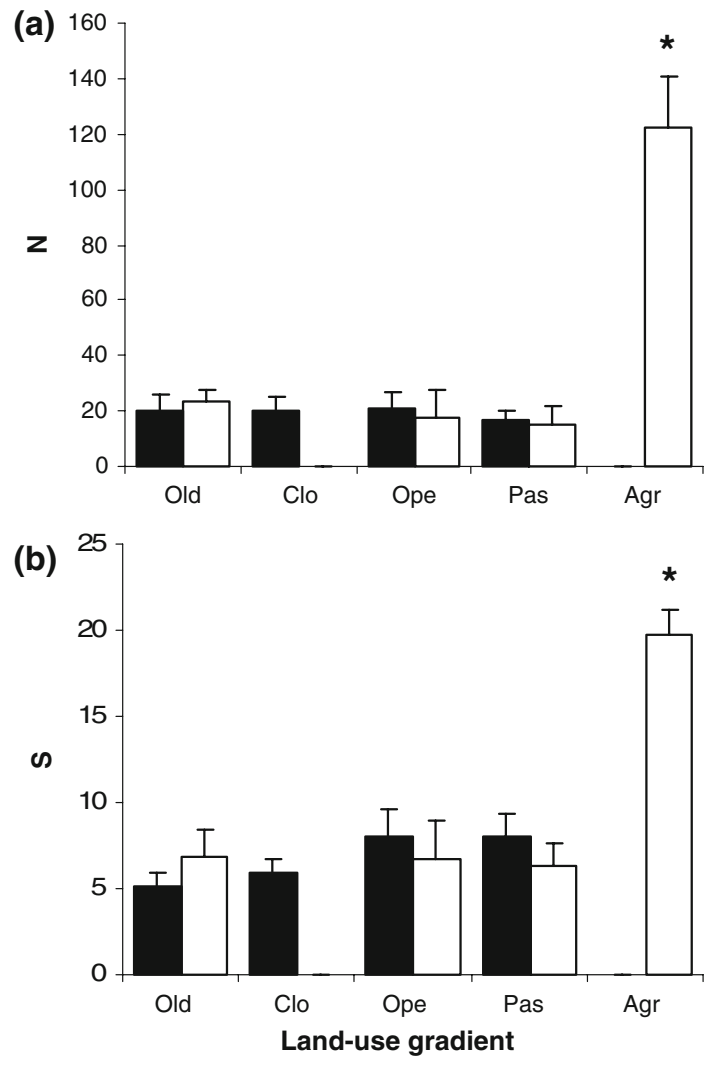
Fig. 3 Randomised accumulation curves for the rove beetles' species richness recorded in the different landscape types

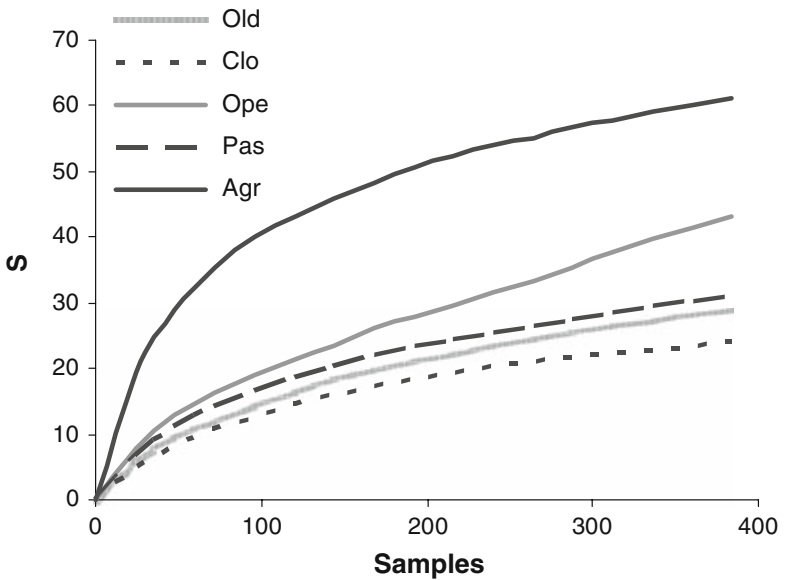

sp. (7.85\%) and Quedius cobosi Coiffait (5.82\%) (Table 2). Thirteen species were sub-dominant (1-5\%) and all others rare (29 species were singletons). The overall taxonomic composition of dominant and subdominant species was strongly influenced by the agriculture site (Table 2). In fact, although X. longiventris, A. bipustulata and Philonthus cognatus Stephens were dominant (as well as Megalinus glabratus Gravenhorst was subdominant) in the agriculture, they were rare or even did not occur in the other landscapes. Inversely, $O$. aethiops was strongly dominant in old-growth and closed montados and also dominant in more open mosaics, but less common in agriculture. Moreover, Sepedophilus

Table 2 Rank $(R)$ and percentage (\%) of dominant (more than 5\% of relative abundance) and sub-dominant species $(1-5 \%)$

\begin{tabular}{|c|c|c|c|c|c|c|c|c|c|c|c|c|}
\hline & \multicolumn{2}{|c|}{ Old } & \multicolumn{2}{|c|}{ Clo } & \multicolumn{2}{|c|}{ Ope } & \multicolumn{2}{|l|}{ Pas } & \multicolumn{2}{|c|}{ Agr } & \multicolumn{2}{|c|}{ Total } \\
\hline & $\mathrm{R}$ & $\%$ & $\mathrm{R}$ & $\%$ & $\mathrm{R}$ & $\%$ & $\mathrm{R}$ & $\%$ & $\mathrm{R}$ & $\%$ & $\mathrm{R}$ & $\%$ \\
\hline Atheta sp. & 6 & 3.2 & 9 & 1.6 & 3 & 11 & 8 & 3.5 & 1 & 28 & 1 & 19 \\
\hline Xantholinus longiventris Heer & * & & & & $* *$ & & 6 & 4.7 & 2 & 19 & 2 & 12 \\
\hline Aleochara bipustulata (Linnaeus) & & & & & $*$ & & & & 3 & 15 & 3 & 8.9 \\
\hline Ocypus aethiops (Waltl) & 1 & 50 & 2 & 21 & 6 & 5.6 & 5 & 5 & 25 & 0.2 & 4 & 8.5 \\
\hline Sepedophilus sp. & 4 & 6.7 & 1 & 48 & 4 & 9.7 & 2 & 14 & & & & 7.9 \\
\hline Quedius cobosi Coiffait & 7 & 2 & 11 & 1.2 & 1 & 19 & 4 & 7.4 & 5 & 4.9 & 6 & 5.8 \\
\hline Atheta & 2 & 11 & 5 & 2.8 & 5 & 8.6 & 11 & 2.3 & 7 & 3.8 & 7 & 4.8 \\
\hline Ocypus olens Müller & $*$ & & 3 & 6.8 & 2 & 15 & 1 & 22 & 10 & 1.3 & 8 & 4.8 \\
\hline Philonthus cognatus $\mathrm{St}$ & & & & & & & & & 4 & 5 & 9 & 3 \\
\hline Megalinus glabratus & & & & & $*$ & & 8 & 3.5 & 6 & 3.9 & 10 & 2.8 \\
\hline Quedius & 9 & 1.5 & 8 & 1.9 & 7 & 5.3 & 7 & 4.3 & 9 & 1.5 & 11 & 2.1 \\
\hline nitidulus (Fabricius) & 3 & 8.5 & & & 10 & 2.2 & 7 & 4.3 & 20 & 0.5 & 13 & 1.8 \\
\hline Quedius semiaeneus (Stephens) & 10 & 1.2 & 14 & 0.9 & $*$ & & 9 & 3.1 & 8 & 1.8 & 14 & 1.6 \\
\hline Xantholinu & 10 & 1.2 & 4 & 5 & 12 & 0.9 & 3 & 9.7 & & & 15 & 1.5 \\
\hline Quedius latinus Gridelli & $* *$ & & $*$ & & 8 & 5 & & & 12 & 1.1 & 16 & 1.3 \\
\hline Quedius nigriceps Kraatz & 5 & 4.4 & 7 & 1.9 & 12 & 0.9 & & & 22 & 0.4 & 17 & 1 \\
\hline
\end{tabular}

Shaded numbers indicate the three more abundant species in each landscape type

*Singletons; **doubletons 


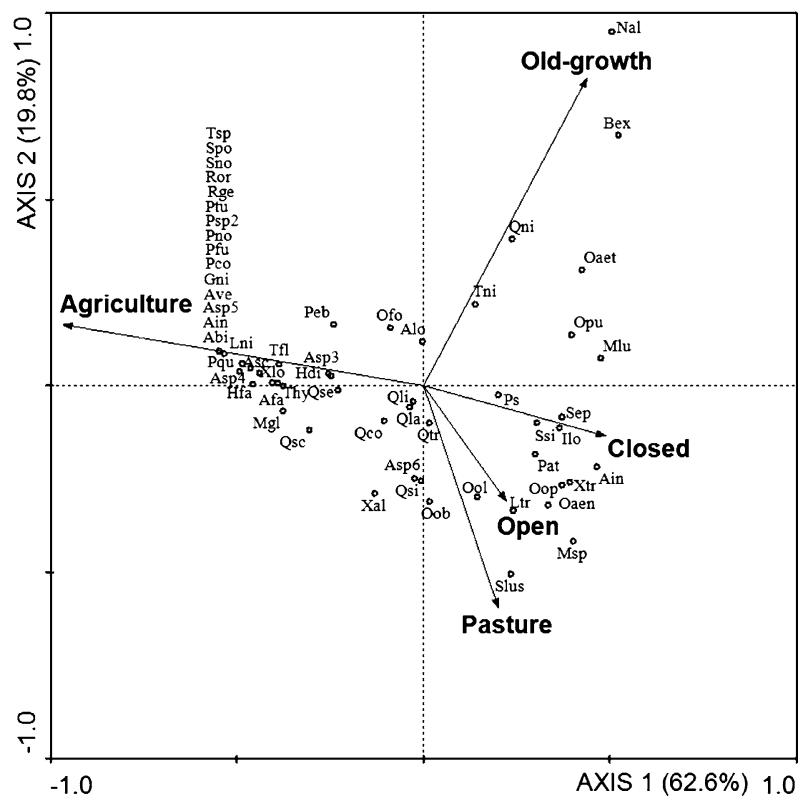

Fig. 4 CCA based on rove beetle community composition of the different landscape types. Significance of canonical axes: axis $1, F=12.5(P<0.01)$; other axes, $F=5.561(P<0.01)$

sp. was the most dominant in closed montados, as well as Q. cobosi and Ocypus olens Müller were the most common species in mosaics dominated by open woodlands and pastures, respectively.

From the 12 endemic species found along the landscape types, only one was dominant (Q. cobosi), one was sub-dominant (Xantholinus translucidus Scriba: $1.5 \%$ ) and the other ten were rare. Of these, two were exclusives from old-growth forest (Nazeris algarvensis Coiffait, Nazeris ibericus Koch), two were exclusives from open montado (Leptobium doderoi Gridelli, Parameropaederus lusitanicus (Aubé)) and two were exclusives from agriculture (Achenium hartungi Wollaston, Scopaeus portai lusitanicus Luze).

Regarding beetle diversity patterns, a DCA revealed an unimodal relationship to the land-use gradient (axis 1: eigenvalue $=0.55$, gradient length $=3.98 \mathrm{SD}$ ). The same analysis was made for ground beetles which also showed an unimodal relationship to the gradient (axis 1: eigenvalue $=0.63$, gradient length $=3.77 \mathrm{SD}$ ). Accordingly, a CCA was performed for both families and clearly separated agriculture area from the cork-oak mosaics along the first canonical axis (explaining 62.6 and $50.6 \%$ of the variability for rove and ground beetles, respectively; Figs. 4, 5). The second canonical axis of the CCA (explaining 19.8 and $20.8 \%$ of the variability, respectively) discriminated beetle species composition among the cork-oak mosaics. A clear differentiation between landscapes dominated by closed woodlands (old-growth and closed montado, on the positive side) from the more open landscapes (open montado and mosaics dominated by pastures, on the negative side) occurred in the case of ground beetles (Fig. 5). Concerning rove beetles, oldgrowth (on the positive side) detached from the other cork-oak mosaics (on the negative side), mainly due to the occurrence of some rare species, such as Bolitobius exoletus Erichson (coded "Bex" in Fig. 4) and the endemics Medon lusitanicum Coiffait ("Mlu") and N. algarvensis Coiffait ("Nal"). 


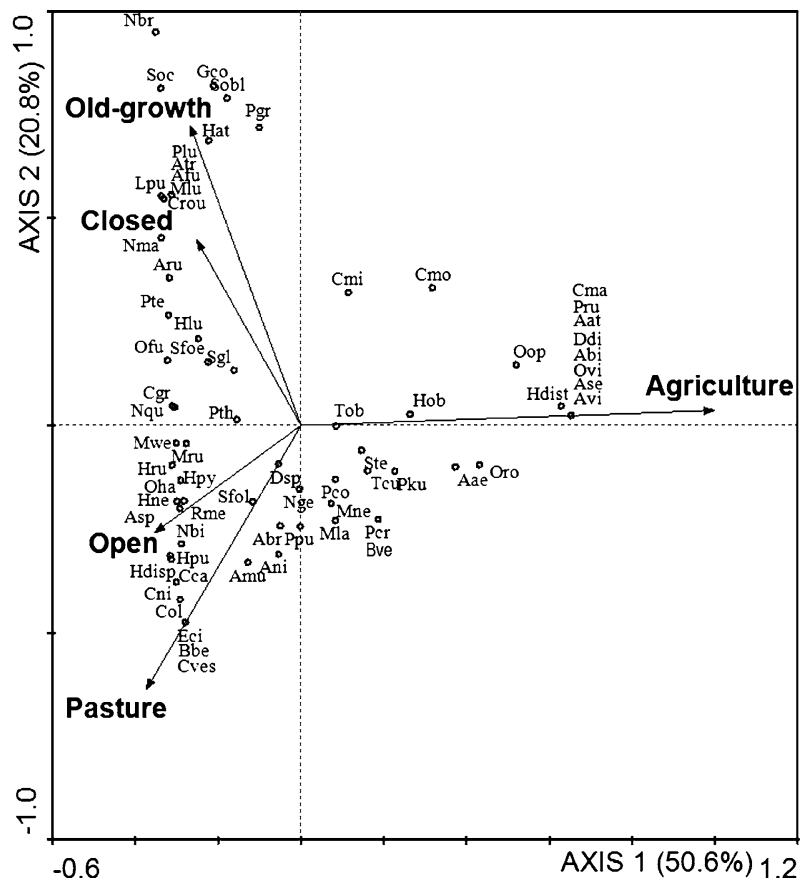

Fig. 5 CCA based on ground beetle community composition of the different landscape types. Significance of canonical axes: axis $1, F=12.3(P<0.01)$; other axes, $F=7.25(P<0.01)$

\section{Indicators of land-use}

Regarding the indicator value analysis, 32 rove beetle species as well as 24 species from the ground beetle data of Martins da Silva et al. (2008) were common enough to be tested, i.e. recorded an IndVal value equal or superior to 25 (Figs. 6, 7). All but two rove beetle species, as well as two ground beetles species, exhibited significant indicator value $(P<0.05)$ for at least one, or combination of some, landscape type(s). Concerning rove beetles, 22 species (more than 70\%) displayed their highest indicator value for agriculture (Fig. 8). Aleochara bipustulata (99.7) and X. longiventris (95.8) recorded the highest indicator values and thereby were considered specialists of this site (Fig. 6). Only $29 \%$ of taxa, namely Sepedophilus sp., O. aethiops, X. translucidus and O. olens, recorded higher indicator values for the cork-oak mosaics. Nevertheless, Sepedophilus sp. (81) was considered a specialist of closed montados. Ocypus aethiops also fitted as a fairly stenotopic species of forest landscapes although its higher indicator value (76.2 in the old-growth mosaic) did not reach the 80 . This species was replaced for $O$. olens in landscape types dominated by open areas (open montado and pastures), where $O$. olens, a well as $Q$. cobosi, were more common (Fig. 6). Concerning ground beetles, nine species (40\%) recorded the highest indicator value for agriculture (Fig. 8). Three species, i.e. Campalita maderae (Fabricius), Pseudophonus rufipes (De Geer) and Harpalus distinguendus (Duftschmid), were considered specialists of agricultural areas. Furthermore, C. maderae and P. rufipes recorded the maximum (100) indicator value for this area. More than $60 \%$ of ground beetle species, but particularly Rhabdotocarabus melancholicus Breuning, Hadrocarabus lusitanicus (Fabricius), Steropus globosus (Quensel) and Calathus granatensis Vuillefroy, 


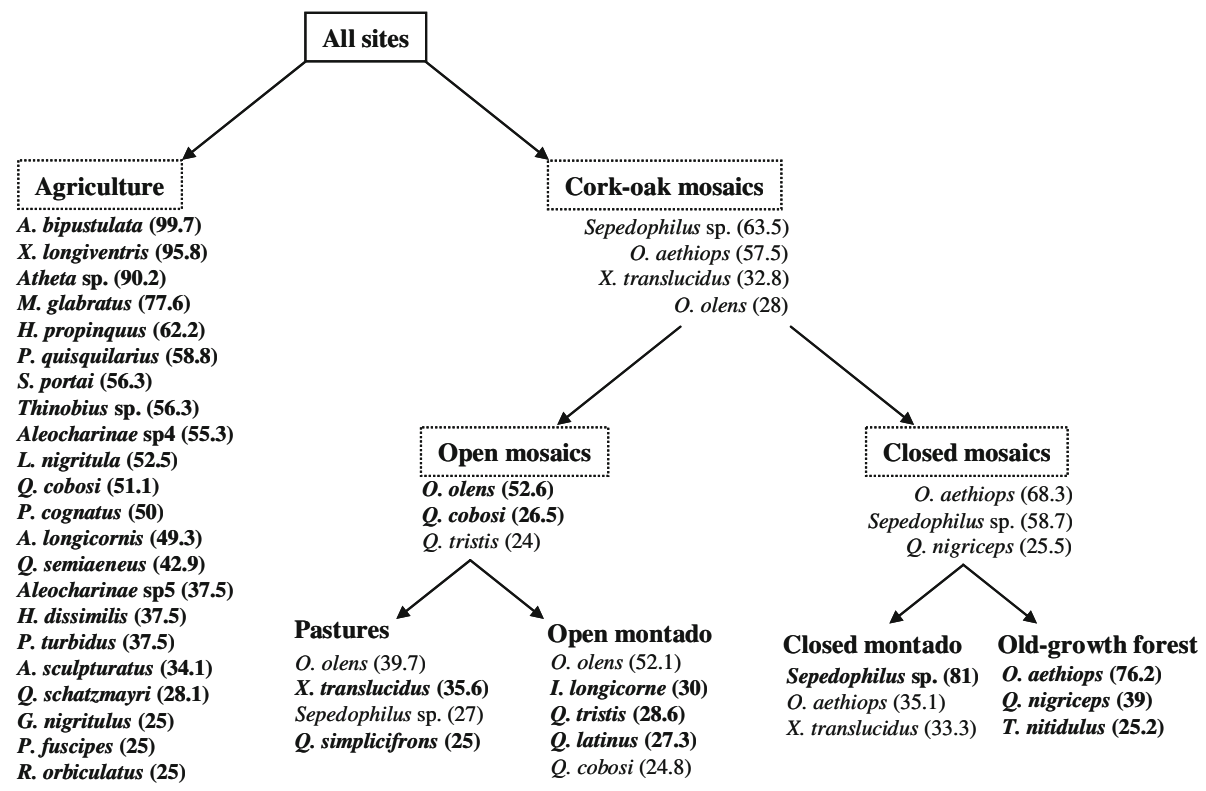

Fig. 6 Rove beetle indicator species (indicator values sensu Dufrêne and Legendre 1997) superimposed on the site cluster obtained from a clustering method based on the Bray-Curtis similarity distances. All indicator species with significant $(P<0.05)$ indicator values are included (indicator value is given in parenthesis). The maximum indicator value of each species is indicated in bold

recorded higher indicator values for the cork-oak mosaics (Fig. 7). From these, 39\% of species were indicators of landscapes dominated by open areas. Rhabdotocarabus melancholicus was deemed to be specialist of montados dominated by pastures $($ IndVal $=89.5)$, while $C$. granatensis recorded the higher indicator value for montados dominated by open woodlands. A lower number of species (about 22\%), particularly $H$. lusitanicus and S. globosus, were more associated to closed mosaics. Moreover, H. lusitanicus and $S$. globosus revealed a more or less eurytopic distribution within overall mosaic landscapes, despite the highest indicator value of $S$. globosus (75.9) was attained for the closed montado (Fig. 7).

\section{Discussion}

General response to land-use intensification

In line with the results from ground beetles (Martins da Silva et al. 2008), the highest species richness and abundance of rove beetles were recorded in the extremely homogeneous and frequently disturbed area: the agricultural landscape. Considerable evidence from other studies, concerning rove and ground beetles, is also consistent with this result (e.g. Buse and Good 1993; Magura et al. 2001; Brose 2003; Vanbergen et al. 2005). In fact, the positive response of both beetle families to land-use intensification was expected considering that generalists and open-habitat beetles are usually dominant in terms of abundance and richness in the species assemblages of pitfall samples (Kromp 1999; Heliölä et al. 2001; Larsen et al. 2003). It seems hence reasonable to presume that a major 


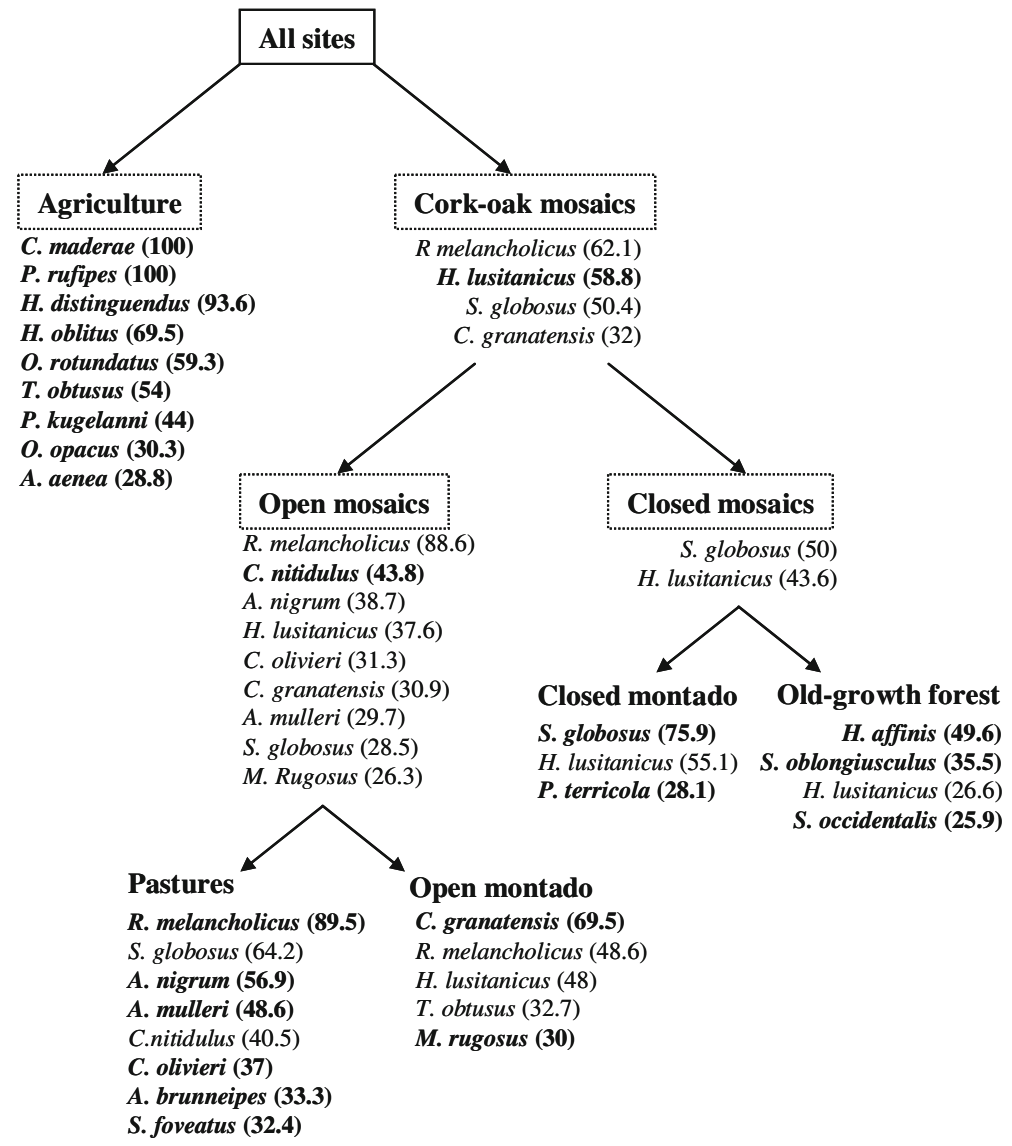

Fig. 7 Ground beetle indicator species (indicator values sensu Dufrêne and Legendre 1997) superimposed on the site cluster obtained from a clustering method based on the Bray-Curtis similarity distances. All indicator species with significant $(P<0.05)$ indicator values are included (indicator value is given in parenthesis). The maximum indicator value of each species is indicated in bold

Fig. 8 Relative number of rove and ground beetles' indicator species found for each landscape type along the land-use gradient

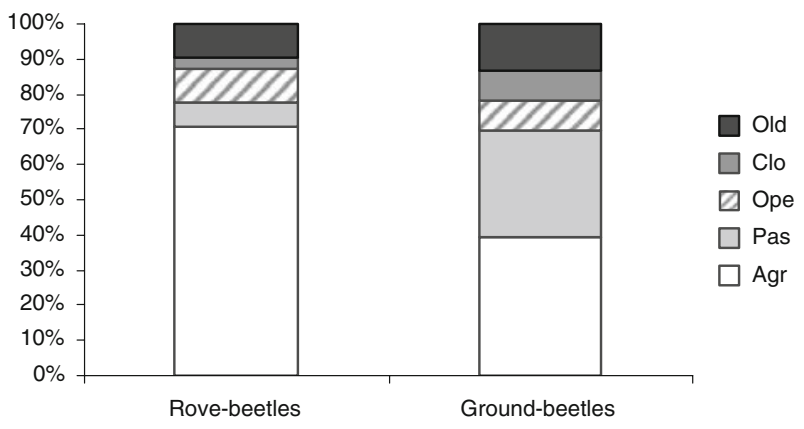

part of these soil dwelling beetles have found in the monoculture a large amount of suitable habitat (e.g. moisture conditions of the permanently irrigated alfalfa field) and resource availability sustaining their higher activity. Concerning beetle diversity patterns agriculture 
communities clearly differed from all other landscape types, showing the importance of agriculture areas for species turnover within the dynamic forest-agriculture fragmented landscapes (e.g. Buse and Good 1993). Moreover, according to the indicator value analysis (Dufrêne and Legendre 1997), a considerable number of beetle species were found as specialists of agriculture areas. These results highlight the key role of some epigaeic predators (e.g. C. maderae) as well as parasitoids (e.g. A. bipustulata) as pest controllers in typical Mediterranean agro-ecosystems.

\section{Woodland beetles as indicators}

Ground beetles showed a considerable higher number of indicator species associated to the cork-oak mosaics in comparison with rove beetles (see Fig. 8). Nevertheless, most of ground beetle species were apparently less negatively affected by the land-use intensification gradient within the mosaic landscapes. Most species were indicators of landscapes dominated by open woodlands or pasture habitats and one was considered a specialist of this latter landscape typology. A lesser relative number of indicator species were more associated to mosaics dominated by closed woodlands. Moreover, although some ground beetle species had already been designated as old-growth specialists in previous studies (e.g. Spence et al. 1996; Magura et al. 2001; Paquin 2008), no old-growth woodland specialists (according to Pohl et al. 2007) were found here. Concerning rove beetles, despite the relative lower number of indicators found for the cork-oak mosaics, one taxon (Sepedophilus sp.) was considered a specialist for landscapes dominated by closed woodlands. In fact, most species of the genus Sepedophilus (subfamily Tachyporinae) are deemed to be primarily associated with fungous in decaying wood and hence they are largely found in bark or litter of ancient broad-leaved woodlands (Alexander 2002). Moreover, other rove beetle species (O. aethiops) was "almost" a specialist for old-growth woodlands. The application of the IndVal at the landscape level revealed a higher fidelity of some rove beetle species to mosaics with higher cover of cork-oak woodlands. Such species could therefore be more threatened by the effects of land-use intensification in Mediterranean agro-forest landscapes. Regarding the CCA analysis, Carabidae communities were able to unambiguously discriminate diversity patterns of closed-woodland mosaics from more open landscapes, revealing a stronger connection with the a priori landscape typology than rove beetles. On the other hand, Staphylinidae communities were able to discriminate the old-growth woodland from the agro-forest managed mosaics. Some species that were not common enough to be tested in the indicator value analysis, one of them is endemic ( $N$. algarvensis), supported the distinctive pattern of this landscape type in relation to the others. The association of some rove beetle species to particular mature forests was found in other studies, indicating their higher response to a finer scale of habitat variation in relation to ground beetles (Pohl et al. 2007).

Having said this, it is not negligible to observe that sampling effort of this study, based on pitfall traps like most rove beetle studies (e.g. Shah et al. 2003; Lawes et al. 2005; Hofmann and Mason 2006; Pohl et al. 2007), was not sufficient to completely assess species richness, particularly in the forested sites where the habitat vertical structure is much more complex than in cultivated areas. Therefore, a substantial number of opportunistic staphylinid predators and fungivorous species could probably be widely dispersed all over the forest habitat besides the soil. For instance, Duelli and Obrist (1998) found that window flight interception traps efficiently collect rove beetles with good flight ability. Particularly, the use of ground based and trunk-window traps have adequately recorded saproxylic rove beetles such as Lordithon and Sepedophilus spp. (e.g. Kaila et al. 1997; 
Sverdrup-Thygeson 2001; Müller et al. 2008). Hence, considerable more rove beetle species and possibly more forest specialists could be found using complementary sampling methods.

Conservation relevance and conclusions

Despite the general positive response of these epigaeic beetles to the land-use intensification, conservation prioritisation should not be given only on the basis of species richness, but rather focus on those potentially more susceptible to habitat loss and fragmentation (Gutiérrez et al. 2004). This is the case of the woodland sensitive beetles (e.g. Halme and Niemelä 1993; Sroka and Finch 2006; Spitzer et al. 2008) particularly in Mediterranean agro-forest landscapes. Although forest indicator species (according to Dufrêne and Legendre 1997) were scarcely found in this study, some rare and endemic rove beetle species characterised old-growth cork-oak woodlands, highlighting their importance as key-habitats (sensu Tews et al. 2004) for biodiversity conservation. In fact, regardless the suitability of the "indicator value method" for the identification of characteristic species of certain habitats, the use of rare species (and particularly endemics) has been indicated as an essential tool for typifying areas of high conservation potential (e.g. Kerr 1997; Anderson and Ashe 2000; Borges et al. 2000; Pykälä et al. 2005; Bates et al. 2007). Considering the added value of $Q$. suber cover for the protection of sensitive rove and ground beetles, it would be necessary to strengthen the connectivity of cork-oak patches in agricultural Mediterranean landscapes. This management practice could compensate for isolation between local populations, enhancing dispersal and long-term survival of rove and ground beetles' metapopulations at the landscape level (Petit and Usher 1998; Magura et al. 2000, 2001). Species turnover between agriculture crops and woodland field boundaries would also improve the pest-control service provided by most rove and ground beetles (e.g. Woodcock et al. 2005), enhancing the sustainable use of Mediterranean agro-forestry systems. In fact, besides conservation purposes, other motivations for biodiversity assessment such as pest control, but also ecological resilience and ecosystem functioning (e.g. Bengtsson 1998; Duelli and Obrist 2003) could benefit from the integration of rove beetles (along with ground beetles) in the "indicator basket" (sensu Duelli and Obrist 2003; Lawes et al. 2005) of sampling protocols, considering their extensive richness and wide range of size groups, trophic habits, habitat width and life forms (e.g. Bohac 1999).

Acknowledgments This study was sponsored by the EU, integrated in the BIOASSESS project (Contract No. EVK4-1999-00280). The authors would like to thank the Administration of Companhia das Lezírias (in the person of Eng. Sérvulo Correia) and the Força Aérea Portuguesa-Campo de Tiro de Alcochete (in the person of Cmte Norte Jacinto) for allowing the realisation of the field work. Martins da Silva was supported by the Portuguese Foundation for Science and Technology (SFRH/BD/37976/2007).

\section{References}

Alexander KNA (2002) The invertebrates of living and decaying timber in Britain and Ireland: a provisional annotated checklist. English Nature Research Reports, 467. English Nature, Peterborough

Andersen A, Eltun R (2000) Long-term developments in the carabid and staphylinid (Col., Carabidae and Staphylinidae) fauna during conversion from conventional to biological farming. J Appl Entomol 124:51-56. doi:10.1046/j.1439-0418.2000.00438.x

Anderson RS, Ashe JS (2000) Leaf litter inhabiting beetles as surrogates for establishing priorities for conservation of selected tropical montane cloud forests in Honduras, Central America (Coleoptera; Staphylinidae, Curculionidae). Biodivers Conserv 9:617-653. doi:10.1023/A:1008937017058 
Bates AJ, Sadler JP, Fowles AP (2007) Livestock trampling reduces the conservation value of beetle communities on high quality exposed riverine sediments. Biodivers Conserv 16:1491-1509. doi: 10.1007/s10531-006-9028-7

Bengtsson J (1998) Which species? What kind of diversity? Which ecosystem function? Some problems in studies of relations between biodiversity and ecosystem function. Appl Soil Ecol 10:191-199. doi: 10.1016/S0929-1393(98)00120-6

Bohac J (1999) Staphylinid beetles as bioindicators. Agric Ecosyst Environ 74:357-372. doi:10.1016/ S0167-8809(99)00043-2

Borges PAV, Serrano ARM, Quartau JA (2000) Ranking the Azorean Natural Forest Reserves for conservation using their endemic arthropods. J Insect Conserv 4:129-147. doi:10.1023/A:1009629012205

Brose U (2003) Regional diversity of temporary wetland carabid beetle communities: a matter of landscape features or cultivation intensity? Agric Ecosyst Environ 98:163-167. doi:10.1016/S0167-8809 (03)00078-1

Buddle CM, Langor DW, Pohl GR, Spence JR (2006) Arthropod responses to harvesting and wildfire: implications for emulation of natural disturbance in forest management. Biol Conserv 128:346-357

Buse A, Good JEG (1993) The effects of conifer forest design and management on abundance and diversity of rove beetles (Coleoptera: Staphylinidae): implications for conservation. Biol Conserv 64:67-76. doi: 10.1016/0006-3207(93)90384-D

Coiffait H (1972) Coléoptères Staphylinidae de la region paléarctique occidentale I. Généralités. Sous familles: Xantholininae et Leptotyphlinae. Nouv Rev Entomol 2:1-651

Coiffait H (1974) Coléoptères Staphylinidae de la region paléarctique occidentale, II. Sous famille Staphylininae, Tribus Philonthini et Staphylinini. Nouv Rev Entomol 4:1-593

Coiffait H (1978) Coléoptères Staphylinidae de la region paléarctique occidentale, III. Sous famille Staphylininae, Tribus Quediini et Sous famille Paederinae, Tribo Pinophilini. Nouv Rev Entomol 8: $1-364$

Coiffait H (1982) Coléoptères Staphylinidae de la region paléarctique occidentale, IV. Sous famille Paederinae, Tribo Paederini 1 (Paederini, Lathrobii). Nouv Rev Entomol 12:1-440

Coiffait H (1984) Coléoptères Staphylinidae de la region paléarctique occidentale, V. Sous famille Paederinae, Tribo Paederini 2 et Sous famille Euaesthetinae. Nouv Rev Entomol 13:1-424

Drugmand D, Outerelo R (1997) Les Staphylinidae endémiques de l'ouest de l'Europe continentale (Coleoptera): premiers résultats. Documents de travail de l'Institut royal des Sciences naturelles de Belgique 87: 1-150

Duelli P, Obrist MK (1998) In search of the best correlates for local organismal biodiversity in cultivated areas. Biodivers Conserv 7:297-309. doi:10.1023/A:1008873510817

Duelli P, Obrist MK (2003) Biodiversity indicators: the choice of values and measures. Agric Ecosyst Environ 98:87-98. doi:10.1016/S0167-8809(03)00072-0

Dufrêne M, Legendre P (1997) Species assemblages and indicator species: the need for a flexible assymetrical approach. Ecol Monogr 67:345-366

Freude H, Harde KW, Lohse GA (1964) Die Käfer Mitteleuropas, Band 4: Staphylinidae I (Micropeplinae bis Tachyporinae). Goecke \& Evers Verlag, Krefeld 264 pp

Gutiérrez D, Menéndez R, Méndez M (2004) Habitat-based conservation priorities for carabid beetles within the Picos de Europa National Park, northern Spain. Biol Conserv 115:379-393. doi:10.1016/ S0006-3207(03)00154-X

Halme E, Niemelä J (1993) Carabid beetles in fragments of coniferous forest. Ann Zool Fenn 30:17-30

Heliölä J, Koivula M, Niemelä J (2001) Distribution of carabid beetles (Coleoptera, Carabidae) across boreal forest-clear-cut ecotone. Conserv Biol 15:370-377. doi:10.1046/j.1523-1739.2001.01500 2370.x

Hofmann TA, Mason CF (2006) Importance of management on the distribution and abundance of Staphylinidae (Insecta: Coleoptera) on coastal grazing marshes. Agric Ecosyst Environ 114:397-406. doi: 10.1016/j.agee.2005.12.001

Hortal J, Borges PAV, Gaspar C (2006) Evaluating the performance of species richness estimators: sensitivity to sample grain size. J Anim Ecol 75:274-287. doi:10.1111/j.1365-2656.2006.01048.x

Kaila L, Martikainen P, Punttila P (1997) Dead trees left in clearcuts benefit saproxylic Coleoptera adapted to natural disturbances in boreal forest. Biodivers Conserv 6:1-18. doi:10.1023/A:1018399401248

Kerr JT (1997) Species richness, endemism, and the choice of areas for conservation. Conserv Biol 11:1094-1100. doi:10.1046/j.1523-1739.1997.96089.x

Kotze DJ, O’Hara RB (2003) Species decline-but why? Explanations of carabid beetle (Coleoptera, Carabidae) declines in Europe. Oecologia 135:138-148

Kromp B (1999) Carabid beetles in sustainable agriculture: a review on pest control efficacy, cultivation impacts and enhancement. Agric Ecosyst Environ 74:187-228. doi:10.1016/S0167-8809(99)00037-7 
Larsen KJ, Work TT, Purrington FF (2003) Habitat use patterns by ground beetles (Coleoptera: Carabidae) of northeastern Iowa. Pedobiologia (Jena) 47:288-299. doi:10.1078/0031-4056-00192

Lawes MJ, Kotze DJ, Bourquin SL, Morris C (2005) Epigaeic invertebrates as potential ecological indicators of Afromontane forest condition in South Africa. Biotropica 37:309-318

Magura T, Tóthmérész B, Bordán Z (2000) Effects of nature management practice on carabid assemblages (Coleoptera: Carabidae) in a non-native plantation. Biol Conserv 93:95-102. doi:10.1016/S00063207(99)00073-7

Magura T, Tóthmérész B, Molnár T (2001) Forest edge and diversity: carabids along forest-grassland transects. Biodivers Conserv 10:287-300. doi:10.1023/A:1008967230493

Markgraf A, Basedow T (2002) Flight activity of predatory Staphylinidae in agriculture in central Germany. J Appl Entomol 126:79-81. doi:10.1046/j.1439-0418.2002.00607.x

Martins da Silva P, de Faria e Silva I, Boieiro M, Aguiar CAS, Serrano ARM (2006) Four new records to the rove-beetle fauna of Portugal (Coleoptera, Staphylinidae). Bol Soc Entomol Aragonesa 39:397-399

Martins da Silva P, Aguiar CAS, Niemelä J, Sousa JP, Serrano ARM (2008) Diversity patterns of groundbeetles (Coleoptera: Carabidae) along a gradient of land-use disturbance. Agric Ecosyst Environ 124:270-274. doi:10.1016/j.agee.2007.10.007

Moreno CE, Halffter G (2000) Assessing the completeness of bat biodiversity inventories using species accumulation curves. J Appl Ecol 37:149-158. doi:10.1046/j.1365-2664.2000.00483.x

Müller J, Bußler H, Kneib T (2008) Saproxylic beetle assemblages related to silvicultural management intensity and stand structures in a beech forest in Southern Germany. J Insect Conserv 12:107-124. doi: 10.1007/s10841-006-9065-2

Niemelä J, Baur B (1998) Threatened species in a vanishing habitat: plants and invertebrates in calcareous grasslands in the Swiss Jura mountains. Biodivers Conserv 7:1407-1416. doi:10.1023/A:1008835 529764

Niemelä J, Langor DW, Spence JR (1993) Effects of clear-cut harvesting on boreal ground-beetle assemblages (Coleoptera: Carabidae) in western Canada. Conserv Biol 7:551-561. doi:10.1046/j.15231739.1993.07030551.x

Outerelo R, Gamarra P (1985) Las familias y géneros de estafilínidos de la península Ibérica. Claves para la identificación de la Fauna Española, 10. Cátedra de Entomología. Facultad de Biología, Universidad Complutense, Madrid, $139 \mathrm{pp}$

Paquin P (2008) Carabid beetle (Coleoptera: Carabidae) diversity in the black spruce succession of eastern Canada. Biol Conserv 141:261-275. doi:10.1016/j.biocon.2007.10.001

Petit S, Usher MB (1998) Biodiversity in agricultural landscapes: the ground beetle communities of woody uncultivated habitats. Biodivers Conserv 7:1549-1561. doi:10.1023/A:1008875403868

Pohl GR, Langor DW, Spence JR (2007) Rove beetles and ground beetles (Coleoptera: Staphylinidae, Carabidae) as indicators of harvest and regeneration practices in western Canadian foothills forests. Biol Conserv 137:294-307. doi:10.1016/j.biocon.2007.02.011

Pykälä J, Luoto M, Heikkinen RK, Kontula T (2005) Plant species richness and persistence of rare plants in abandoned semi-natural grasslands in northern Europe. Basic Appl Ecol 6:25-33. doi:10.1016/ j.baae.2004.10.002

Rainio J, Niemelä J (2003) Ground beetles (Coleoptera: Carabidae) as bioindicators. Biodivers Conserv 12:487-506. doi:10.1023/A:1022412617568

Romero-Alcaraz E, Ávila JM (2000) Landscape heterogeneity in relation to variations in epigaeic beetle diversity of a Mediterranean ecosystem. Implications for conservation. Biodivers Conserv 9:985-1005. doi:10.1023/A:1008958720008

Shah PA, Brooks DR, Ashby JE, Perry JN, Woiwod IP (2003) Diversity and abundance of the coleopteran fauna from organic and conventional management systems in southern England. Agric For Entomol 5:51-60. doi:10.1046/j.1461-9563.2003.00162.x

Sousa JP, Gama MM, Pinto C, Keating A, Calhôa F, Lemos M, Castro C, Luz T, Leitão P, Dias S (2004) Effects of land-use on Collembola diversity patterns in a Mediterranean landscape. Pedobiologia (Jena) 48:609-622. doi:10.1016/j.pedobi.2004.06.004

Sousa JP, Bolger T, Gama MM, Lukkaric T, Ponge JF, Simón C, Traser G, Vanbergen AJ, Brennan A, Dubs F, Ivitis E, Keating A, Stofer S, Watt AD (2006) Changes in Collembola richness and diversity along a gradient of land-use intensity: a pan European study. Pedobiologia (Jena) 50:147-156. doi: 10.1016/j.pedobi.2005.10.005

Spence JR, Langor DW, Niemelä J, Cárcamo HA, Currie CR (1996) Northern forestry and carabids: the case for concern about old-growth species. Ann Zool Fenn 33:173-184

Spitzer L, Konvicka M, Benes J, Tropek R, Tuf IH, Tufova J (2008) Does closure of traditionally managed open woodlands threaten epigeic invertebrates? Effects of coppicing and high deer densities. Biol Conserv 141:827-837. doi:10.1016/j.biocon.2008.01.005 
Sroka K, Finch O-D (2006) Ground beetle diversity in ancient woodland remnants in north-western Germany (Coleoptera, Carabidae). J Insect Conserv 10:335-350. doi:10.1007/s10841-006-9008-y

Sverdrup-Thygeson A (2001) Can 'continuity indicator species' predict species richness or red-listed species of saproxylic beetles? Biodivers Conserv 10:815-832. doi:10.1023/A:1016679226554

Taboada A, Kotze DJ, Salgado JM, Tárrega R (2006) The influence of habitat type on the distribution of carabid beetles in traditionally managed "dehesa" ecosystems in NW Spain. Entomol Fenn 17:284293

Tews J, Brose U, Grimm V, Tielbörger K, Wichmann MC, Schwager M, Jeltsch F (2004) Animal species diversity driven by habitat heterogeneity/diversity: the importance of keystone structures. J Biogeogr 31:79-92

Vanbergen AJ, Woodcock BA, Watt AD, Niemelä J (2005) Effect of land-use heterogeneity on carabid communities at the landscape scale. Ecography 28(1):3-16. doi:10.1111/j.0906-7590.2005.03991.x

Verdú JR, Crespo MB, Galante E (2000) Conservation strategy of a nature reserve in Mediterranean ecosystems: the effects of protection from grazing on biodiversity. Biodivers Conserv 9:1707-1721. doi:10.1023/A:1026506725251

Woodcock BA, Westbury DB, Potts SG, Harris SJ, Brown VK (2005) Establishing field margins to promote beetle conservation in arable farms. Agric Ecosyst Environ 107:255-266. doi:10.1016/j.agee. 2004.10.029 